This item was submitted to Loughborough's Research Repository by the author.

Items in Figshare are protected by copyright, with all rights reserved, unless otherwise indicated.

\title{
The effect of actuator nozzle designs on the electrostatic charge generated in pressurised metered dose inhaler aerosols
}

PLEASE CITE THE PUBLISHED VERSION

https://doi.org/10.1007/s11095-014-1529-6

\section{PUBLISHER}

(c) Springer

VERSION

AM (Accepted Manuscript)

\section{PUBLISHER STATEMENT}

This work is made available according to the conditions of the Creative Commons Attribution-NonCommercialNoDerivatives 4.0 International (CC BY-NC-ND 4.0) licence. Full details of this licence are available at: https://creativecommons.org/licenses/by-nc-nd/4.0/

\section{LICENCE}

CC BY-NC-ND 4.0

\section{REPOSITORY RECORD}

Chen, Yang, Paul M. Young, David F. Fletcher, Hak Kim Chan, Edward J. Long, David Lewis, Tanya Church, and Daniela Traini. 2019. "The Effect of Actuator Nozzle Designs on the Electrostatic Charge Generated in Pressurised Metered Dose Inhaler Aerosols". figshare. https://hdl.handle.net/2134/35040. 
The effect of actuator nozzle design on the electrostatic charge generated in pressurised metered dose inhaler aerosols

Yang Chen ${ }^{1}$, Paul M. Young ${ }^{1}$, David F. Fletcher ${ }^{2}$, Hak Kim Chan ${ }^{3}$, Edward Long ${ }^{4}$, David Lewis ${ }^{5}$, Tanya Church $^{5}$, Daniela Traini ${ }^{1 *}$

${ }^{1}$ Respiratory Technology, Woolcock Institute of Medical Research and Discipline of Pharmacology, Sydney Medical School, The University of Sydney, NSW 2037, Australia.

${ }^{2}$ School of Chemical and Biomolecular Engineering, The University of Sydney, NSW 2006, Australia

${ }^{3}$ Advanced Drug Delivery Group, Faculty of Pharmacy (A15), University of Sydney Sydney, NSW 2006, Australia

${ }^{4}$ Wolfson School of Mechanical and Manufacturing Engineering, Loughborough University, Loughborough, Leicestershire, LE11 3TU United Kingdom

${ }^{5}$ Chiesi Ltd, Units T1 - T3, Bath Rd. Ind. Est., Chippenham, Wiltshire, SN14 0AB United Kingdom

*To whom correspondence should be addressed

Daniela Traini

Tel: +61 291140352

Email: Daniela.traini@sydney.edu.au

Keywords: electrostatics charges, metered dose inhalers, nozzle designs, triboelectric series. 


\section{$1 \quad$ Introduction}

Pressurised metered dose inhalers (pMDI) were first developed in 1956 and are now a widely used device for pulmonary drug delivery. Their major components include a canister, a metering valve and an actuator; and they rely on the energy generated from the pressurised propellant to atomize the suspended or solubilized active pharmaceutical ingredients and excipients (1). Upon actuation, the channel connecting the canister to the metering valve is opened, allowing the formulation from the valve reservoir to flow into the expansion chamber of the pMDI device (2). The rapid decrease in pressure causes the liquid propellant to flash and a transfer of some of the liquid phase to the vapor phase of the formulation occurs through bubble nucleation and growth (3). This primary atomization is called flash evaporation or flash boiling and introduces large contact/friction areas between evaporating droplets and the surface wall of the actuator nozzle (4).

When two materials make contact with each other, due to the differences in the material properties (i.e. work function), electrostatic charges will transfer from one material to another to equalize electrostatic potential. When the two materials are separated, the electron transfer from one material to the other can cause one material to bear negative charges and leave the other positively charged due to loss of electrons. This process is called triboelectrification and is the mechanism that causes aerosols emitted from a pMDI to carry electrostatic charges $(5,6)$. The attractive and repulsive forces between such charged species can significantly influence the downstream behavior of the aerosols, and hence plays an important role in drug deposition (7). Theoretical studies carried out during the late 1970s and early 1980s 
established that a significant increase in deposition is achievable by charged particles under suitable conditions (8-11). This finding was then supported by in vitro and in vivo experimental studies using lung models, animals and human subjects (12-17). Although many of these studies have demonstrated that aerosol electrostatics can influence particle deposition, the degree of change will depend on the magnitude and polarity of the acquired static charges. Still, for pMDIs the mechanisms and influential factors behind the electrostatic charge profiles of the aerosol cloud still remain unclear. This is largely due to the complexity of the actuation process of the pMDIs, where rapid flash-boiling and liquid-gas-solid interaction introduces challenges for the study of electrostatic generation, accumulation and relaxation on both the actuator materials and within the aerosol cloud. Furthermore, since triboelectrification depends largely on the materials' properties, such as conductivity and electrostatic potential, there are other confounding factors that can complicate the study of electrostatic in pMDIs including moisture contents, surface condition and environmental conditions etc.

There are three ways to acquire charges during contact/friction charging: electron, ion and material transfer (18). Electron transfer is the dominant mechanism for triboelectrification, especially for conducting material such as metals. As electrons can move relatively freely within the entire conductor body, the accumulated charges on the conducting material often demonstrate a uniform polarity (19). This creates an electric field within the conductor material, mostly concentrated at the sharp edges of the material itself (20). The redistribution of the build-up of electrons will then concentrate at those sharp edge regions and eventually lead to dielectric breakdown of the surrounding air, with consequent spark electrostatic discharge (21-23). 
Electron transfer is also believed to be the charging mechanism for insulators, such as polymers used in pMDIs actuators. However, recent studies have proposed that transfer of ions that may already be present on the polymer's surface or are acquired from the atmospheric moisture content, could be the main mechanism for static charging of thermoplastic materials $(21,24-26)$, and the polarity of such acquired charges will depend largely on the acidity and basicity of the polymeric structure. Unlike conductors, where built-up charges are distributed throughout the material, insulators are unable to allow deep penetration or free movement of electrostatic charge. Consequently, the accumulated charge would be localised on isolated spots on the insulator's surface, with different polarity distributions (26). Electrostatic discharges also arise from insulating materials present at the surface with highest curvature. However, multiple accumulated charge spots on a single insulator surface could discharge simultaneously and lead to brush-like electrostatic discharge (27). Small material fragment transfer from surface to surface has also been reported as a source of static charge generation for both conducting and insulating materials, however, this mechanism is believed to be less important and largely dependent on the surface roughness of the material (28); furthermore, with respect to pMDI formulations, this factor can be ruled out since it would have been reported at an early stage due to the robust quality and regulatory requirements that medical devices are subjected.

Although it is not well recognized in the pharmaceutical industry, electrostatic discharge has been well investigated in other industrial areas, including particle separation (e.g. recycling) and powder/fuel processing (e.g. mining) (29, 30). Other 
factors that could influence the nature of the electrostatic discharge include chemical/physical properties of the charged surface, surface geometry and the magnitude and polarity of the electrostatic charge $(21,22)$.

With respect to pMDIs, in a previous study, the effect of the actuator nozzle design flat versus cone, were shown to greatly influence the electrostatic charging dynamics of a beclomethasone dipropionate solution based pMDI aerosol (31). It was shown that by 'smoothing' the sharp edges of the actuator, the polarity of the charge profile for the pMDI aerosol with an insulator actuator material like PTFE was reversed (32). This study extends the previous investigation to include four actuator nozzle designs and three actuator materials, conductors and insulators selected from the triboelectric series, to further assess their influence on pMDI aerosols triboelectrification.

\section{$2 \quad$ Materials and Methods}

\section{$2.1 \quad$ Materials}

The pMDI actuator blocks with different nozzle designs were manufactured using three materials selected from the triboelectric series, including one conducting material, aluminium (Aalco Metals Ltd, Cobham, UK), and two insulating materials, polyethylene terephthalate (PET) and polytetrafluoroethylene (PTFE) (Ensinger GmbH, Nufringen, Germany), respectively. The pMDI device comprised a $50 \mu \mathrm{l}$ metered valve (Batch BK0313029) consisting of an aluminium ferrule, polyester/nylon body, EPDM/NBR/Butyle seats and gasket, acetal/polyester metering chamber and stainless steel spring all from Bespak Europe Ltd (Norfolk, UK) and equipped with standard aluminium pMDI canister C128P (Batch 1002043-3, 19 ml 
brim capacity) from Presspart Manufacturing Ltd (Lancashire, UK). The propellant 1,1,1,2-Tetrafluoroethane (HFA 134a) was obtained from INEOS Fluor Americas

LLC (LA, USA). Beclomethasone dipropionate was supplied by Chiesi Farmaceutici S.p.A (Parma, Italy). The water used throughout the study was purified by reverse osmosis (Milli-Q, Sydney, Australia) and all analytical grade chemicals were from Sigma-Aldrich Pty Ltd (Castle Hill, Australia).

\subsection{Pressurised metered dose inhaler formulations}

Four pMDI formulations investigated were prepared according to Table 1. Anhydrous ethanol or Ethanol with solubilized BDP was accurately weighted into the aluminium canister based on the weight calculated according to the desired dose. The canister was then immediately crimped with a $50 \mu \mathrm{l}$-metering valve and pressure filled with HFA 134a propellant using a Pamasol Laboratory plant P2016 (Pamasol Willi Maäden AG, Pfaffikon, SZ). Solubility of the drug components was confirmed visually using glass canisters (Saint Gobain plc). All canisters were stored at ambient temperature for 24 hours prior to testing.

\subsection{Actuator nozzle designs and manufacture}

Actuators with a $0.3 \mathrm{~mm}$ nominal atomization orifice diameter and $1 \mathrm{~mm}$ jet length nozzle were manufactured from the actuator blocks using PTFE, PET and aluminium. At the exit of the atomization orifice, four types of nozzles namely flat, curved flat, cone and curved cone (Figure 1) were designed using Siemens NX software and engineered using high speed-steel cutting tools. The components were water cooled 
during manufacture in order to maintain their dimensional accuracy. Orifice diameters were checked using spatially calibrated microscope and MediaCybernetics Image-Pro software, where dimensional accuracy to within $\pm 0.01 \mathrm{~mm}$ was achieved.

All actuator blocks were placed in a sonicator bath and washed with water and ethanol followed by air-drying before the initial use. Custom-made adaptors used to house the actuator blocks and allowing connection to the United States Pharmacopeia (USP) induction port with the impactor were designed using computer aided design (ANSYS DesignModeler release 13, ANSYS Inc, PA, USA) and built in acrylonitrile butadiene styrene (ABS) using a rapid prototype 3D printer (Dimension Elite, MN, USA).

\subsection{Measurement of the aerosol electrostatic charge}

The electrical low-pressure impactor (ELPITM, Dekati, Ltd, Finland) was used for electrostatic charge and drug deposition measurements of the pMDI formulations at a flow rate of $28.3 \pm 1.5 \mathrm{~L} / \mathrm{min}$. The ELPI is a 13-stage impactor with aerodynamic diameter cut-off range between $0.028 \mu \mathrm{m}$ and $10.07 \mu \mathrm{m}$, with each impaction stage isolated and connected to an individual digital ammeter that records current in femto amps per second (fA/s). The USP induction port was fitted to the modified ELPI where the corona charger was removed to allow the native electrostatic charge measurement of the pMDI aerosols clouds.

Prior to analysis, the pMDI formulations were shaken thoroughly and primed to waste twice using a commercial actuator. The canister was then fitted to the in-house-built 
adaptor unit containing the actuator and connected to the ELPI via the USP Induction port and corona frame. The flow rate was set at $28.3 \pm 1.5 \mathrm{~L} / \mathrm{min}$ using a Sogevac ${ }^{\circledR}$ model SV25 vacuum pump (Leybold, France) and calibrated using a Copley® model 4000 flow meter (Nottingham, UK). The electrometer baseline for the ELPI was zeroed after the peak flow rate was achieved. Five single doses from each pMDI formulation (equivalent to $250 \mu \mathrm{g}$ total dose of BDP) were dispersed into the ELPI with a 30 s delay between each actuation to ensure a drug per stage deposition above analytical limit of detection.

During aerosols dispersion, current versus time data from each ELPI stage were collected and recorded by ELPI-VI 4.0 software (Dekati Ltd, Finland). The data were integrated to produce charge data. After all five actuations, the adaptor, USP induction port, corona frame and impactor stages were washed with methanol/ $\mathrm{H}_{2} \mathrm{O}$ $(80: 20 \mathrm{v} / \mathrm{v})$ rinsing solution into suitable volumetric flasks. The recovered drug samples were analysed using high-performance liquid chromatography (HPLC). No chemical analyses were performed for drug free pMDIs containing HFA, HFA-1\% and HFA-15\% only. In these cases, only charge data were collected and analysed. All experiments were randomized and performed in triplicate under laboratory environment conditions (temperature $\sim 25^{\circ} \mathrm{C}$ and relative humidity $\sim 40-50 \%$ )

\subsection{Quantification assay of drug deposits by HPLC}

The drug deposition of BDP was analysed by HPLC using a Shimadzu prominence UFLC system equipped with an SPD-20A UV-vis detector, LC-20AT solvent delivery unit, SIL-20A HT autosampler (Shimadzu Corporation, Japan) and a $3.9 \times$ 
150 mm Nova-Pak ${ }^{\circledR}$ C18 column (Waters Corporation, Milford, MA, USA) with mobile phase (68:32 \% v/v, methanol and $0.05 \% \mathrm{w} / \mathrm{v}$ ammonia acetate aqueous solution). The sample injection volume was $100 \mu \mathrm{l}$ and the peak detection was achieved at UV $240 \mathrm{~nm}$ with $1 \mathrm{~mL} / \mathrm{min}$ flow rate and integrated using Shimadzu LCSolution workstation software (Shimadzu Corporation, Japan). BDP standards were prepared daily in rinsing solution. Linearity of BDP was obtained between 1 and $50 \mu \mathrm{g} / \mathrm{mL}\left(\mathrm{R}^{2}=0.999\right)$ with a retention time of $\sim 5$ minutes.

\subsection{Data Analysis}

The charge data on each stage were derived from the electric current data recorded by the ELPI during the actuation period of the pMDI. The net charge for each experiment was calculated based on the total charge of the 13 stages of the ELPI impactor. The mass recovery data for formulation BDP were calculated as the total mass of the five consecutive actuations. The total dose (TD), emitted dose (ED), USP deposition (USP), fine particle fraction (FPF), mass median aerodynamic diameter (MMAD) and geometric standard deviation (GSD) were calculated and analysed. MMAD were calculated assuming linearity between $84-16 \%$ of the cumulative mass undersize lognormal distribution and the GSD was determined as $\left(\mathrm{d}_{0.84} / \mathrm{d}_{0.16}\right)^{1 / 2}$. Electrostatic and mass deposition data were expressed as the mean charge and mass per stage for three replicate experiments, consisting of five consecutive shots. Two sample Student t-test (heteroscedastic) and one-way ANOVA (unstacked) analysis were performed using the STATPlus ${ }^{\circledR}$ statistics software package (AnalystSoft Inc, VA, USA). Significant difference was based on $\mathrm{p}<0.05$. 


\section{$3 \quad$ Results and Discussion}

The effect of actuator nozzle designs on pMDI aerosols electrostatic charges and aerosols performance have been investigated and results are discussed below.

\subsection{PTFE actuator}

In the current study, PTFE was selected as the insulating actuator material representing the most electronegative polymer in the triboelectric series (33). After contact with other materials, PTFE has a high tendency to become negatively charged, leading the material in contact to become positively charged. During repeated actuations, negative charges can build up on the PTFE actuator surface, leading to electron leakage or possible electrostatic discharge to the surrounding area, especially when a sharp edge is present, as in the cone orifice design of the actuator (Figure 1). The dispersed negative charges consequently could influence the positive charges carried by the aerosol within the travelling plume.

3.1.1 The effect of nozzle design on net charges of different pMDI formulations

The total net charge of the four orifice designs with PTFE are shown in Figure 2. With the pMDI formulation containing only the propellant HFA 134a (Formulation HFA), all four nozzles produced negative charged aerosols; with both flat and cone curved designs showing significantly reduced charge magnitudes (Student t-test, $\mathrm{p}<$ 0.05). These results differ from predictions that could be drawn from the triboelectric properties of PTFE, possibly due to the highly electronegative fluorine elements 
within the HFA 134a molecular structure. The fluorine elements could compete with the PTFE material for electrons, resulting in negative charged aerosols.

By including the curved edge design within the actuator, it was anticipated that there would be a reduction of electron accumulation at the sharp edges of the actuator and consequently a reduced electrostatic discharge would occur to neutralise the plume net charge. However, both the curved flat and curved cone nozzles, with HFA only formulation, demonstrated significant reduced charge magnitude (Figure 2). As discussed previously, insulating materials can carry both negative and positive charges on the same surface at the same time, depending on the properties of the area of contact. The curved design of the nozzle could change the surface property of the actuator material, with positive charges distributed more evenly compared with a nozzle with sharp edges. Negative charged aerosol could be neutralised due to the positive electric field present on the nozzle surface, consequently reducing the overall plume net charge.

Compared with the HFA only formulation, when $1 \%$ ethanol co-solvent was introduced (HFA-1\%), a significant reduction in the negative charge magnitude was observed for flat and curved flat nozzles (Figure 2, Student t-test, $\mathrm{p}<0.05$ ), while cone and curved cone nozzles changed their charge polarity to positive. At 15\% ethanol co-solvent concentration (HFA-15\%), the negative net charges for flat and curved flat nozzles remained unchanged in comparison with HFA-1\% ethanol, but the two cone nozzles showed significantly different net charges compared with HFA-1\% formulations. 
Propellant HFA 134a alone would be considered to be an insulating liquid, as its dielectric constant is 9.8 (34). The addition of ethanol as co-solvent in the formulation changes the electrostatic potential of the propellant, via: (A) molecule interactions between ethanol and HFA, that reduces the negativity of the fluorine elements; (B) increased overall conductivity of the propellant by ionisation of the ethanol (35); or (C) change in chemical composition of the propellant due to water content present in the solvent (36). At the same time, the presence of ethanol also reduces the evaporation rate of the aerosol, increasing the contact time between the droplet and the actuator material. When a large surface area is available, such as the outer shape in the cone and curved cone nozzles, the electrons from the negative charged aerosol may have more interactions with the positive charged actuator surface, reducing the negative charge and shifting to a total net positive polarity (Figure 2).

With the pMDI formulation containing BDP and 15\% ethanol (formulation BDP), both flat and cone designs with sharp edges produced electropositive charges significantly different (Student t-test, $\mathrm{p}<0.05$ ) to the electronegative charges of the curved flat and cone nozzles, respectively (Figure 2). For all four-nozzle designs the BDP formulation compared with drug free HFA-15\% (one-way ANOVA, $\mathrm{p}<0.05$ ), showed significantly higher charge magnitudes, regardless of the polarity. Similarly to our previous investigation, these results demonstrated that BDP did reduce the effect of ethanol on supressing the charge generations for the aerosols (37), and at the same time, reduced the negativity of the propellant. 
3.1.2 The effect of PTFE nozzle designs on the aerosol performance of BDP pMDI formulation

Since the actuator nozzle is a critical component in the atomisation process of a pMDI, its diameter will have a role in determining the aerosol particle size. Thus, it is important to investigate how nozzle designs influence aerosol performance and how they correlate with the net charge profiles.

Cumulative percentage particle mass distributions were calculated from the drug mass recovered off the impactor stages and are shown in Figure 3. The total ex-valve dose (TD), emitted dose (ED), deposition in USP region (USP), fine particle fraction less than $6.66 \mu \mathrm{m}$ (FPF), mass median aerodynamic diameter (MMAD) and geometric standard deviation (GSD) are listed in Table 2. No statistically significant differences (one-way ANOVA) for MMAD (average $0.78 \mu \mathrm{m} \pm 0.01$ ) were found for the four nozzle designs. Furthermore, the particle size distributions (PSD, Figure 3) also showed no significant differences between all nozzle designs (ANOVA, p>0.05). These results demonstrate that nozzle design has no influence on particle size distribution for pMDI formulations.

Further analysis also showed no statistical difference in total ex-valve dose emitted for the four PTFE actuator designs. However, with the drug deposition in the USP region, both curved flat and curved cone orifices demonstrated a significantly higher deposition, compared with flat and cone designs, respectively (Student t-test, $\mathrm{p}<0.05$ ). This lead to reduced drug stage deposition and consequently reduced FPF for the curved nozzle designs (Table 2). While it has not been well investigated for 
pharmaceutical aerosols, the effect of nozzle design has been extensively investigated in agricultural systems where different nozzle shapes have been used for specific irrigation purposes, such as fine mist and wider spray coverage $(38,39)$. It is possible that the curved designs could have influenced the plume shape, resulting in increased deposition in the USP throat region. It is also interesting to notice that both high USP throat depositions with the curved flat and curved cone nozzles are associated with reversed aerosol charge polarity (Figure 2). Figure 4 summarizes the charge to mass ratio for all PTFE actuator orifice designs. Both curved nozzle designs showed reversed charge polarity for the entire particle sizes distribution. The charge magnitudes were similar for curved flat and curved cone designs, suggesting the nozzle design has no effect on the charge distribution for the aerosol, but significantly influence the charge polarity and throat deposition.

\subsection{PET actuator}

Actuator material PET is another insulating thermoplastic material selected for this study. It has a similar electrostatic potential to PTFE, but with a triboelectric ranking between neutral and negative (33). Therefore, contact charging with PET has a high tendency for bipolar charges and gives more variable net charge profiles. This is reflected in the highly variable net charge data for PET nozzles for all pMDI formulations investigated, as shown in Figure 5.

3.2.1 The effect of PET nozzle design on net charges with different pMDI formulations 
Generally, net charges produced with PET actuators had a higher magnitude compared with PTFE (Figure 2). This could be a result of charge neutralisation between the strong electrostatic potential difference between PTFE actuator surface and the pMDI aerosols after contact charging, hence results in a lesser net charge profile. The PET actuator with flat nozzle design and HFA only formulation resulted in the highest negative charge of $-1735.29 \pm 167.17 \mathrm{pC}$, while curved flat shown significantly reduced negative charge magnitude $-314.34 \pm 62.15$ pC. The cone nozzle design has also shown similar negative charge profile $-684.33 \pm 15.80$ pC however, the curved cone nozzle showed a neutral net charge at $-9.83 \pm 77.03$ pC. These results indicate that the PET nozzle designs have a strong influence on aerosol net charges.

When the $1 \%$ ethanol and drug free HFA formulation was used, a significantly reduced negative charge magnitude in comparison with HFA only formulation was observed, with flat and curved flat nozzles (student t-test, $\mathrm{p}<0.5$ ). The curved cone nozzle design showed a positive charge profile at $146.95 \pm 55.15 \mathrm{pC}$, where the cone nozzle showed no difference in charge polarity and magnitude compared with HFA only formulation (Figure 5). When the ethanol concentration was increased to $15 \%$, the net aerosol charge for the PET actuators with curved flat, cone and curved cone nozzle designs all shifted to positive charges, again demonstrating the ability of ethanol to reduce the negative charges of HFA 134a (37).

When BDP was introduced in the formulation, both curved flat and curved cone nozzle designs showed positive net charges, compared with flat and cone designs that resulted in negative charges. A significant (Student t-test $\mathrm{p}<0.05$ ) reversed charge 
polarity was also shown for the PET curved actuator nozzles (Figure 5). As discussed before, PET charges negatively according to the triboelectric series (33). However, similar to PTFE, the ability of PET to attract and accumulate electrons on its surface is overwhelmed by the strong electronegativity of HFA 134a. Therefore, the aerosol net charge after contact with the actuator material is negatively charged. The cosolvent ethanol increases the conductivity of the formulation, as well as introducing potential moisture content in the plume. This could lead to semi-conducting aerosol droplets formation and wetting of the actuator orifice surface. Both conditions will alter the contact charging properties for the actuator and the aerosols. Therefore, an increase in positive charge is observed (Figure 5).

\subsubsection{The effect of nozzle designs on PET aerosols performance}

Particle size distributions (Figure 6) for the four PET nozzle designs showed no significant differences. Significantly less ED for cone and curved cone nozzles were observed (Table 2, one way ANOVA, $\mathrm{p}<0.05$ ), compared with flat and curved flat nozzles, possibly due to the larger contact surface area present in the former designs. Although no significant differences were found in the ED for the flat and curved flat PET nozzle, the drug deposition in the USP induction port for the curved flat design was significantly higher than that for the flat nozzle (Student t-test, $\mathrm{p}<0.05$ ). This is reflected in the USP drug deposition of the curved cone nozzle that was found to be higher than that for the cone nozzle (Student t-test, $\mathrm{p}<0.05$ ). Interestingly, high USP depositions for both PET curved nozzles were associated with the reversed net charge polarity (Figure 5), similar to PTFE. Further analyses with charge to mass ratio

(Figure 7) confirmed again, polarity changes were present for all particle sizes. 
However, large variations in the charge to mass ratio were observed for particle sizes larger than $4.04 \mu \mathrm{m}$. A possible reason for this observation is that large aerosol droplets can continue to evaporate after stage impaction, causing fluctuations in the charge data. At the same time, flash evaporation of the propellant is an endothermic reaction that absorbs heat from the surrounding environment. This could cause condensation of water vapour in the air during atomisation hence influencing the charge recording.

\subsection{Aluminium actuator}

Actuator material aluminium is the only conducting material used in the current study. For this material, electron transfer dominates the contact charging mechanism and the free movement of electrons through the material encourages electrostatic intensification at the sharp edges, which could lead to static discharge. In the triboelectric series aluminium is ranked between positive and neutral (33).

3.3.1 The effect of aluminium nozzle designs on net change with different pMDI formulation

The net charges with all nozzle designs and all pMDI formulations for aluminium are shown in Figure 8. In general, aluminium produced net electronegative charge profiles, with magnitudes significantly lower when compared with PET. This is consistent with the triboelectric charging behaviour of aluminium, where the material is classified in the positively charged group and consequently can result in a negative charged aerosol cloud (Figure 8). Concurrently, the high electron conductivity of 
aluminium may allow backflow of electrons from the charged aerosols to the actuator material, resulting in a smaller charge magnitude compared with PET (Figure 5).

Overall, with the HFA only pMDI formulation, the curved flat nozzle produced a significantly (Student t-test $\mathrm{p}<0.05$ ) lower net negative charge compared with the conventional flat nozzle design (Figure 8). For cone designs, the curved cone orifice produced a significantly higher negative charge than the normal cone design (Student t-test $\mathrm{p}<0.05)$. The HFA 134a propellant used in the pMDI formulation is strongly electronegative but is a relatively poor conductor. During contact charging, the propellant grabs electrons from the aluminium actuator where the acquired charges carried by the aerosol would prefer to flow back to the conducting aluminium material. It is envisaged that when a sharp edge is present, as in flat and cone nozzle designs, the positive charge of the aluminium actuator would be concentrated at those edges and attract electron from the aerosols, reducing the negative charge for the aerosols cloud.

However, only the cone nozzle showed this prediction, with minor negative charge compared with the curved cone nozzle. One possible explanation for such a difference between the flat and cone nozzle designs could be due to the contact area during the charging process. A larger surface area allows more interaction between the material and the aerosol cloud. At the same time, two sharp edges, one at the exit of the orifice and one at the opening of the cone design are present in the cone nozzle design, compared with only one sharp edge in the flat nozzle design. This gives a much higher electric field for the cone nozzle to allow electron backflow from the aerosols to the actuator, reducing charge magnitude for this design (Figure 8). 
When $1 \%$ ethanol is present in the pMDI formulation, a similar reduction in negative charge magnitude was observed for the curved flat nozzle compared with the flat nozzle design. Although a reduced negative charge was observed with the curved cone, no statistically significant difference was found when compared with the cone nozzle (Figure 8). With aluminium, 1\% ethanol showed a higher charge magnitude compared with propellant only formulation for flat, curved flat and cone nozzle designs. As mentioned before: the contact charging for a conducting material; such as aluminium, will be dominated by electron transfer and result in a unipolar charged aerosol cloud. The propellant only formulation will have limited capacity for holding electrons after triboelectrification. However, ethanol increases the overall conductivity for the formulation, which allows free movement of electrons through liquid aerosols, increasing the negative charge magnitude of the formulation (Figure 8).

When ethanol concentration is at $15 \%$, the net charges for all nozzle designs are almost neutral (an average of $-68.14 \pm 30.80 \mathrm{pC}$, Figure 8 ) and are significantly lower than the net charge for formulation HFA and HFA-1\%. There are three possible reasons for this: (1) a further increase in the conductivity for the formulation can cause dielectric changes of the aerosols, hence influencing the triboelectrification; (2) molecular interaction between ethanol and HFA 134a could reduce the electronegativity of the propellant; and (3) an increase in bipolar charges due to the presence of ethanol and moisture content in the formulation could cause neutralisation of the overall net charges. 
For BDP, similar charging pattern to HFA-15\% were observed (Figure 8). Statistically significant differences (Student t-test $\mathrm{p}<0.05$ ) in net charge were observed when the curved nozzle designs were compared with conventional nozzles. Both curved flat and curved cone nozzles demonstrated reduced negative charges compared with the flat and cone designs. It is interesting to notice that the curved nozzle designs with an aluminium actuator did not show reversed charge polarity as for PTFE and PET, compared with conventional nozzle designs. It is believed this result is related to the contact charging properties of conducting material that will be discussed in Section 3.4.

\subsubsection{The effect of nozzle designs on aerosol performance for aluminium actuator}

To further understand the relationship between the aerosol charge profiles and the actuator nozzle designs, aerosol performance parameters were analysed. Particle size distributions for aluminium actuators are shown as percentage of cumulative mass undersize in Figure 9. No significant differences were observed for all nozzle designs, except for the cone nozzle at particle size range from 1.62 to $4.02 \mu \mathrm{m}$ (one way ANOVA, $\mathrm{p}<0.05)$. For the aluminium actuator nozzle the design has no significant influence on the aerodynamic particle size distribution of pMDI aerosols.

Further analysis of ED, USP, \% FPF $<6.66 \mu \mathrm{m}$ and MMAD for all nozzle designs are shown in Table 2. No significant differences were observed for MMAD for all nozzle designs, except for aluminium with cone geometry (one way ANOVA, $\mathrm{p}<0.05$ ). This is associated with a lower ED from the pMDI. The aluminium flat nozzle showed the 
highest USP deposition (Table 2), compared with other nozzle designs and is associated with the most electronegative charge profile (Figure 8). This could be the result of plume expansion due to the repulsive force of highly unipolar charged aerosols, indicating that the higher charge magnitude is capable of modifying particle deposition for pMDI.

The charge to mass ratio for all aluminium nozzle designs and BDP pMDI is shown in Figure 10. No significant difference is observed, except for the flat design that showed a negative profile. Large variations observed for the large ( $\geq 4.04 \mu \mathrm{m})$ and small $(\leq 0.159 \mu \mathrm{m})$ particle sizes could be the result of evaporating droplets and limited drug mass recovery from the impactor stages, respectively.

3.4 Overall effect of actuator nozzle designs and materials on aerosol electrostatic charges

As described before, electrons/ions generated from triboelectrification tend to concentrate on sharp edges, consequently, for nozzles designs with such physical characteristics there is the possibility for accumulated electrons/ions to discharge to the surrounding environment, leading to an alteration of the electrostatic charge profiles of the aerosols. Consequently by replacing these 'sharp edges' with curved geometries, the aerosol charge magnitude should have increased, due to a reduced propensity for static discharge and the neutralisation of the charges carried by the plume should have been limited. However, for all three materials investigated, no sudden reduction or increases in charge magnitude was observed for the curved nozzle designs compared with the conventional ones. 
Electrostatic discharge is normally caused by the excess electrons accumulated on a blunt material surface. In this study, PTFE, PET and aluminium actuators have all produced generally positively charged aerosols with drug free pMDI formulations, due to high electronegativity of the HFA 134 propellant. Therefore, the contact charging between the nozzle surface and the aerosols favours electron transfer to the evaporating aerosol droplets. Discharge from a positively charged nozzle surface is highly unlikely and accumulated electrons on the aerosol droplet surface will eventually reach the Rayleigh limit and induce the breakup of the aerosols into smaller droplets.

Meanwhile, as mentioned before, HFA134a is very electronegative and is a relatively poor conductor, and this is reflected by the negative net charge results (Figures 2, 5 and 8). When the co-solvent ethanol is introduced into the formulation, the aerosol generated becomes semi-conductive and electrons/ions are able to move from the nozzle surface to the aerosols and vice versa. This is evident for the formulation containing 15\% ethanol and HFA, where reduced charge magnitudes were observed for all nozzle designs and materials.

The two insulating materials, PTFE and PET, have both shown reversed charge polarity when conventional nozzles were modified to curved designs when tested using BDP pMDI formulation (Figures 2 and 5). It is also interesting to note that the change in net charge polarity for the curved flat and curved cone nozzles was associated with increased USP deposition for the same BDP formulation (Table 2). 
PTFE and PET are both insulating polymers that can generate bipolar charges. For PTFE, as illustrated in Figure 11, the flat nozzle (A) has a narrow orifice, which limits the plume geometry and contact between the aerosols and the actuator material. This is similar for cone designs where a larger surface area allows a longer contact time between the aerosols cloud and the actuator material, but the sharp edge still defines the plume geometry (Figure 11, C). When changed to curved flat and curved cone designs (Figure 11, B and D), the plume shape changes to a wider angle, increasing the chance for electron exchange between the aerosol on the outer region of the plume and the actuator surface. This consequently will allow for the formation of positive charged particles (PTFE, Figure 2) that will largely deposit in the throat region, leaving the impacted particles to be negatively charged for the majority (PTFE, Figure 2). Where for PET, a similar trend for reversed net charge polarity and higher throat deposition were observed, although PET is ranked less negative in the triboelectric series compared with PTFE. Therefore, when the nozzle design was changed to the curved shape, the aerosol that is on the outer edge of the plume is predicted to be negatively charged, leaving the impacted plume core aerosols to be positively charged (PET, Figure 5).

Still, it is not clear that the change in plume shape for both curved nozzle designs are simply due to the change in orifice geometry. Originally, the curved design actuator was selected to investigate the potential electrostatic discharge during the atomisation process. The 'smooth edges' of the curved nozzle could potentially eliminate the electrostatic intensification point and give a more evenly distributed electric field after contact charging (as illustrated by the shaded region in Figure 11, B and D), 
compared with conventional nozzle geometries (Figure 11, A and C). This increased electric field resulting from contact charging could draw the oppositely charged aerosols towards the outer edge of the plume, hence resulting in a wider plume angle and higher induction port deposition.

When aluminium is used for the actuator designs, although a reduced net negative charge was observed with curved flat and curved cone nozzles for BDP pMDI (ALU, Figure 8), there was no reversed charge polarity present and no significantly higher USP deposition (ALU, Table 2). As a conducting material, aluminium generates unipolar charged aerosols that will burst into smaller droplets due to the Raleigh limit during the evaporation process. Smaller droplets with unipolar charges will repel each other and cause plume expansion, increasing the chance of electron exchange with the curved nozzle surface, therefore reducing the charge magnitude in the aluminium actuators. At the same time, plume expansion induces higher deposition in the induction port region. Therefore, lower charge magnitudes were observed with curved nozzle designs for the aluminium actuator (Figure 8).

\section{Conclusions}

This study demonstrated that actuator nozzle designs could significantly influence the electrostatic charge profiles and drug deposition pattern of pMDI aerosols. It was found that curved nozzle designs were able to increase drug deposition to the USP induction port region with reversed charge polarity, especially when using insulating thermoplastics, PTFE and PET, as the actuator material. The results highlighted the 
bipolar charging property of the insulator materials and unipolar charge domination for aluminium conducting material. At the same time, increasing the concentration of co-solvent ethanol used in pMDI formulations is directly linked to reduced charge magnitude, possibly due to an increase in the bipolar charge ratio within the aerosol cloud.

In future, further studies using high-speed imaging and molecular modelling should be used to investigate the actual plume pattern of the different pMDI formulations with different actuator nozzle designs and the electrostatic potentials within the formulation and actuator material at a molecular level.

\section{$5 \quad$ References}

1. Newman SP. Principles of metered-dose inhaler design. Respiratory care. 2005;50(9):1177-90.

2. Clark AR. MDIs: physics of aerosol formation. Journal of aerosol medicine. 1996;9(s1):S-19-S-26.

3. Dunbar C. Atomization mechanisms of pressurized metered dose inhaler Particulate science and technology. 1997;15(3-4):253-71.

4. Sher E, Bar-Kohany T, Rashkovan A. Flash-boiling atomization. Progress in energy and combustion science. 2008;34(4):417-39.

5. Kwok PCL, Glover W, Chan HK. Electrostatic charge characteristics of aerosols produced from metered dose inhalers. Journal of Pharmaceutical Sciences. 2005 Dec;94(12):2789-99. PubMed PMID: ISI:000233733300018.

6. Hoe S, Traini D, Chan HK, Young PM. The Influence of Flow Rate on the Aerosol Deposition Profile and Electrostatic Charge of Single and Combination Metered Dose Inhalers. Pharmaceutical Research. 2009 Dec;26(12):2639-46. PubMed PMID: ISI:000271464100011.

7. Kwok PCL, Chan HK. Electrostatics of pharmaceutical inhalation aerosols. Journal of Pharmacy and Pharmacology. 2009 Dec;61(12):1587-99. PubMed PMID: ISI:000281136700002.

8. $\quad$ Diu CK, Yu CP. Deposition from Charged Aerosol Flows through a Pipe Bend. Journal of Aerosol Science. 1980;11(4):397-402. PubMed PMID:

ISI:A1980KM94500007. 
9. Ingham DB. Precipitation of Charged-Particles in Human Airways. Journal of Aerosol Science. 1981;12(2):131-5. PubMed PMID: ISI:A1981LN21400005.

10. Thiagarajan V, Yu CP. Sedimentation from Charged Aerosol Flows in Parallel-Plate and Cylindrical Channels. Journal of Aerosol Science. 1979;10(4):40510. PubMed PMID: ISI:A1979HT24200007.

11. Yu CP, Chandra K. Precipitation of Submicron Charged-Particles in Human Lung Airways. Bulletin of Mathematical Biology. 1977;39(4):471-8. PubMed PMID: ISI:A1977DL62700007.

12. Chan TL, Yu CP. Charge Effects on Particle Deposition in the Human Tracheobronchial Tree. Annals of Occupational Hygiene. 1982;26(1-4):65-75. PubMed PMID: ISI:A1982PT13100006.

13. Melandri C, Tarroni G, Prodi V, Dezaiacomo T, Formignani M, Lombardi CC. Deposition of Charged-Particles in the Human Airways. Journal of Aerosol Science. 1983;14(5):657-69. PubMed PMID: ISI:A1983RT47400008.

14. Tarroni G, Melandri C, Prodi V, Dezaiacomo T, Formignani M, Bassi P. An Indication on the Biological Variability of Aerosol Total Deposition in Humans. American Industrial Hygiene Association Journal. 1980;41(11):826-31. PubMed PMID: ISI:A1980KN75500008.

15. Ferin J, Mercer TT, Leach LJ. The Effect of Aerosol Charge on the Deposition and Clearance of Tio2 Particles in Rats. Environmental Research. 1983;31(1):148-51. PubMed PMID: ISI:A1983QR93200013.

16. Fraser DA. Deposition of Unipolar Charged Particles in Lungs of Animals. Archives of Environmental Health. 1966;13(2):152-\&. PubMed PMID: ISI:A19668080900003.

17. Vincent JH, Johnston WB, Jones AD, Johnston AM. Static Electrification of Airborne Asbestos - a Study of Its Causes, Assessment and Effects on Deposition in the Lungs of Rats. American Industrial Hygiene Association Journal.

1981;42(10):711-21. PubMed PMID: ISI:A1981MK58000004.

18. Lowell J, Rose-Innes A. Contact electrification. Advances in Physics. 1980;29(6):947-1023.

19. McCarty LS, Whitesides GM. Electrostatic charging due to separation of ions at interfaces: contact electrification of ionic electrets. Angewandte Chemie International Edition. 2008;47(12):2188-207.

20. Greason WD. Investigation of a test methodology for triboelectrification. Journal of Electrostatics. 2000;49(3):245-56.

21. Thomas SW, Vella SJ, Kaufman GK, Whitesides GM. Patterns of electrostatic charge and discharge in contact electrification. Angewandte Chemie.

2008;120(35):6756-8.

22. Greason WD. Electrostatic discharge: a charge driven phenomenon. Journal of electrostatics. 1992;28(3):199-218.

23. Vinson JE, Liou JJ. Electrostatic discharge in semiconductor devices: an overview. Proceedings of the IEEE. 1998;86(2):399-420.

24. Castle G. Contact charging between insulators. Journal of Electrostatics. 1997;40:13-20.

25. Lewis T. Charge transport, charge injection and breakdown in polymeric insulators. Journal of Physics D: Applied Physics. 1990;23(12):1469.

26. Williams MW. Triboelectric charging of insulating polymers-some new perspectives. AIP Advances. 2012;2(1):010701--9.

27. Fredholm O, Lovstrand K. On the discharge of static electricity from an insulator surface. Journal of Physics E: Scientific Instruments. 1972;5(11):1058. 
28. Jasti VK. Electrostatic Charge Generation and Dissipation on Woven Fabrics Treated with Antistatic and Hydrophilic Surface Finishes: North Carolina State University; 2012.

29. Miller HC. Flashover of insulators in vacuum: review of the phenomena and techniques to improved holdoff voltage. Electrical Insulation, IEEE Transactions on. 1993;28(4):512-27.

30. Oda T, Ito Y. Studies on electrostatic surface discharges on corona-charged polymer surfaces. Industry Applications, IEEE Transactions on. 1990;26(4):656-61.

31. Chen Y, Wong WHW, Lewis DA, Church T, Traini D, Young PM.

Triboelectrification Study of a Pressurized Metered Dose Inhaler (pMDI) Formulation Using Different Actuator Materials and Orifice Designs. Respiratory Drug Delivery 2012. 2012; Vol 3:845-50.

32. Chen Y, Traini D, Fletcher DF, Chan HK, Lewis DA, Church T, et al. The Effect of Pressurized Metered Dose Inhaler (pMDI) Actuator Nozzle Design on Triboelectrification and Aerosol Deposition. RDD Europe 2013 (2013). 2013;2:43944.

33. Ndama AT, Guigon P, Saleh K. A reproducible test to characterise the triboelectric charging of powders during their pneumatic transport. Journal of Electrostatics. 2011 Jun;69(3):146-56. PubMed PMID: ISI:000292230300002. 34. Gad SC. Pharmaceutical manufacturing handbook: production and processes: John Wiley \& Sons; 2008.

35. Lewis D. Determination of electrical parameters of some propellants. Personal email communication to the author edMay 2012.

36. Williams III RO, Hu C. Moisture uptake and its influence on pressurized metered-dose inhalers. Pharmaceutical development and technology. 2000;5(2):15362.

37. Chen Y, Young PM, Fletcher DF, Chan HK, Long E, Lewis D, et al. The Influence of Actuator Materials and Nozzle Designs on Electrostatic Charge of Pressurised Metered Dose Inhaler (pMDI) Formulations. Pharmaceutical research. 2013:1-13.

38. Tarjuelo J, Montero J, Carrion P, Honrubia F, Calvo M. Irrigation uniformity with medium size sprinklers. Part II: Influence of wind and other factors on water distribution. Transactions of the ASAE. 1999;42(3):677-89.

39. Lefebvre A. Atomization and sprays: CRC press; 1988. 
$6 \quad$ Tables and Figures 
Table 1: Pressurised metered dose inhalers (pMDIs) formulation compositions

\begin{tabular}{lcccc}
\multicolumn{1}{c}{ Formulations* } & HFA & HFA-1\% & HFA-15\% & BDP \\
\hline Designed Dose $(\mu \mathrm{g})$ & NA & NA & NA & 50 \\
BDP $(\% \mathrm{w} / \mathrm{w})$ & NA & NA & NA & 0.1 \\
Ethanol $(\% \mathrm{w} / \mathrm{w})$ & 0 & 1 & 15 & 15 \\
HFA 134a (\% w/w) & 100 & 99 & 85 & 85 \\
\hline
\end{tabular}

*HFA: HFA 134a used throughout the formulations; BDP: beclomethasone dipropionate;

NA: not applicable. 
Table 2: TD, ED, USP, FPF, MMAD and GSD values for BDP pMDI with different nozzle designs for all three actuator materials ( $\mathrm{n}=3$, mean, $\pm \mathrm{SD}$ ).

PTFE

\begin{tabular}{lcccc}
\hline \multicolumn{1}{c}{ Nozzle Design } & Flat & Curved Flat & Cone & Curved Cone \\
\hline TD $(\mu \mathrm{g})$ & $243.00( \pm 3.62)$ & $254.49( \pm 0.59)$ & $249.33( \pm 3.67)$ & $248.69( \pm 6.40)$ \\
ED (\%TD) & $97.59( \pm 0.21)$ & $95.37( \pm 0.59)$ & $93.87( \pm 0.58)$ & $94.88( \pm 0.14)$ \\
USP (\%TD) & $60.41( \pm 1.68)$ & $74.00( \pm 0.28)$ & $57.58( \pm 1.07)$ & $63.32( \pm 1.69)$ \\
FPF $<6.66 \mu \mathrm{g}(\% \mathrm{TD})$ & $31.94( \pm 1.64)$ & $19.12( \pm 1.14)$ & $31.92( \pm 1.05)$ & $27.34( \pm 2.00)$ \\
MMAD $(\mu \mathrm{m})$ & $0.78( \pm 0.01)$ & $0.76( \pm 0.02)$ & $0.80( \pm 0.01)$ & $0.79( \pm 0.01)$ \\
GSD & $2.16( \pm 0.03)$ & $2.30( \pm 0.02)$ & $2.15( \pm 0.02)$ & $2.15( \pm 0.03)$ \\
\hline
\end{tabular}

PET

\begin{tabular}{lcccc}
\hline \multicolumn{1}{c}{ Nozzle Design } & Flat & Curved Flat & Cone & Curved Cone \\
\hline TD $(\mu \mathrm{g})$ & $244.02( \pm 4.05)$ & $245.99( \pm 4.61)$ & $234.20( \pm 2.71)$ & $250.63( \pm 0.42)$ \\
ED $(\% \mathrm{TD})$ & $96.23( \pm 0.20)$ & $96.67( \pm 0.40)$ & $91.56( \pm 1.35)$ & $94.97( \pm 0.47)$ \\
$\mathrm{USP}(\% \mathrm{TD})$ & $62.14( \pm 1.12)$ & $68.01( \pm 1.43)$ & $56.43( \pm 1.22)$ & $67.71( \pm 2.15)$ \\
FPF $<6.66 \mu \mathrm{g}(\% \mathrm{TD})$ & $28.15( \pm 1.30)$ & $22.83( \pm 2.61)$ & $29.86( \pm 1.24)$ & $22.22( \pm 1.87)$ \\
MMAD $(\mu \mathrm{m})$ & $0.78( \pm 0.00)$ & $0.77( \pm 0.03)$ & $0.79( \pm 0.01)$ & $0.75( \pm 0.01)$ \\
GSD & $2.06( \pm 0.03)$ & $2.04( \pm 0.02)$ & $2.02( \pm 0.02)$ & $2.04( \pm 0.06)$ \\
\hline
\end{tabular}

Aluminium

\begin{tabular}{lcccc}
\hline \multicolumn{1}{c}{ Nozzle Design } & Flat & Curved Flat & Cone & Curved Cone \\
\hline TD $(\mu \mathrm{g})$ & $248.99( \pm 5.76)$ & $234.26( \pm 9.91)$ & $228.20( \pm 1.46)$ & $236.40( \pm 10.67)$ \\
ED $(\% \mathrm{TD})$ & $96.63( \pm 1.17)$ & $96.31( \pm 0.12)$ & $94.35( \pm 0.65)$ & $95.82( \pm 0.80)$ \\
$\mathrm{USP}(\% \mathrm{TD})$ & $66.78( \pm 1.25)$ & $64.63( \pm 0.18)$ & $62.29( \pm 0.36)$ & $63.38( \pm 0.75)$ \\
FPF $<6.66 \mu \mathrm{g}(\% \mathrm{TD})$ & $24.16( \pm 2.19)$ & $26.84( \pm 0.93)$ & $24.20( \pm 1.05$ & $25.39( \pm 0.94)$ \\
MMAD $(\mu \mathrm{m})$ & $0.75( \pm 0.02)$ & $0.77( \pm 0.02)$ & $0.85( \pm 0.02)$ & $0.78( \pm 0.01)$ \\
GSD & $2.07(0.09)$ & $2.04( \pm 0.03)$ & $2.39( \pm 0.14)$ & $2.12( \pm 0.03)$ \\
\hline
\end{tabular}

TD: Total ex-valve dose; ED: emitted dose; FPF: fine particle fraction; MMAD: mass median aerodynamic diameter; GSD: geometric standard deviation. $\mathrm{N}=3$ 


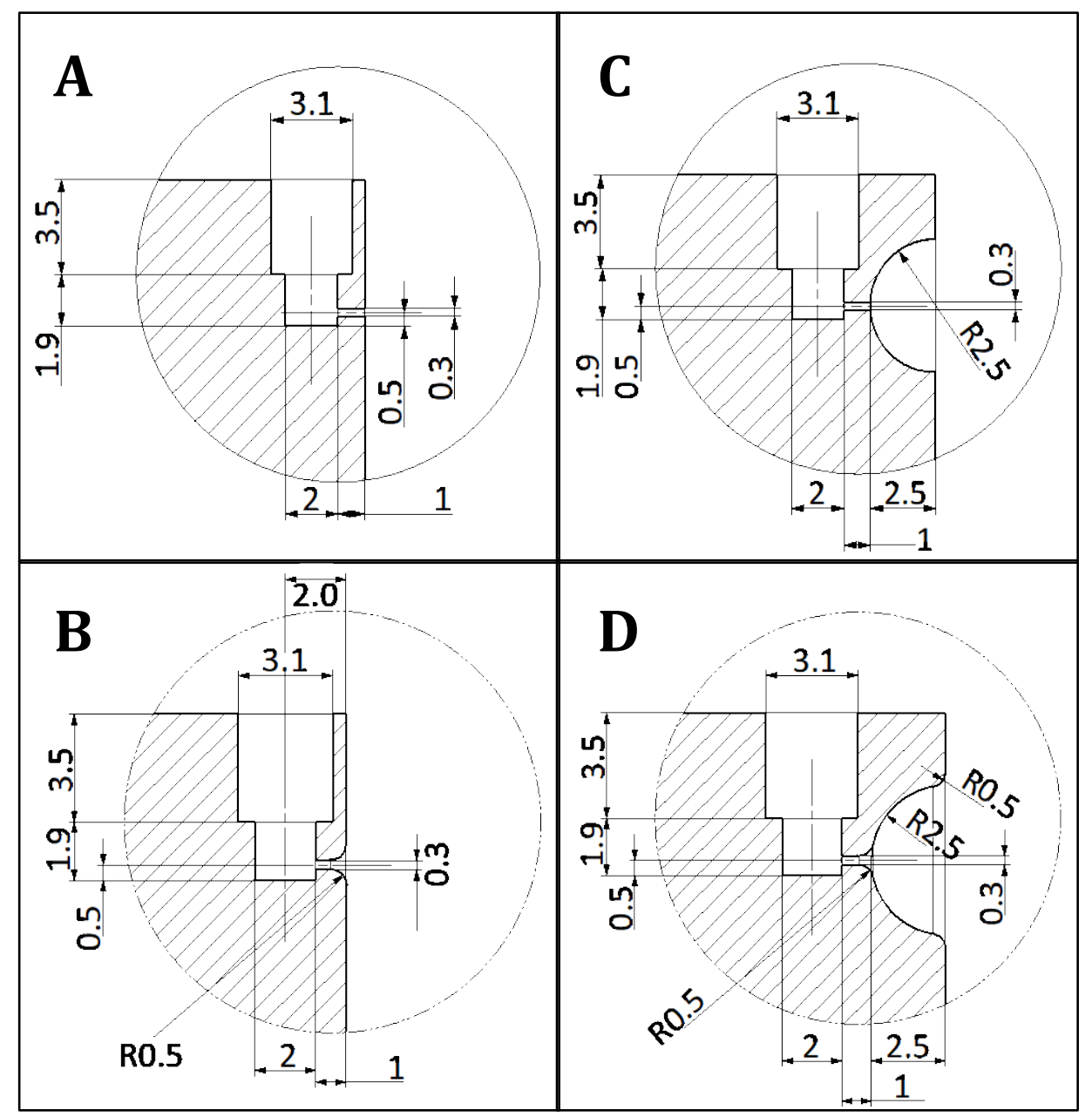

Figure 1: Four nozzle designs with A: Flat; B: Curved Flat; C: Cone and D: Curved Cone. 


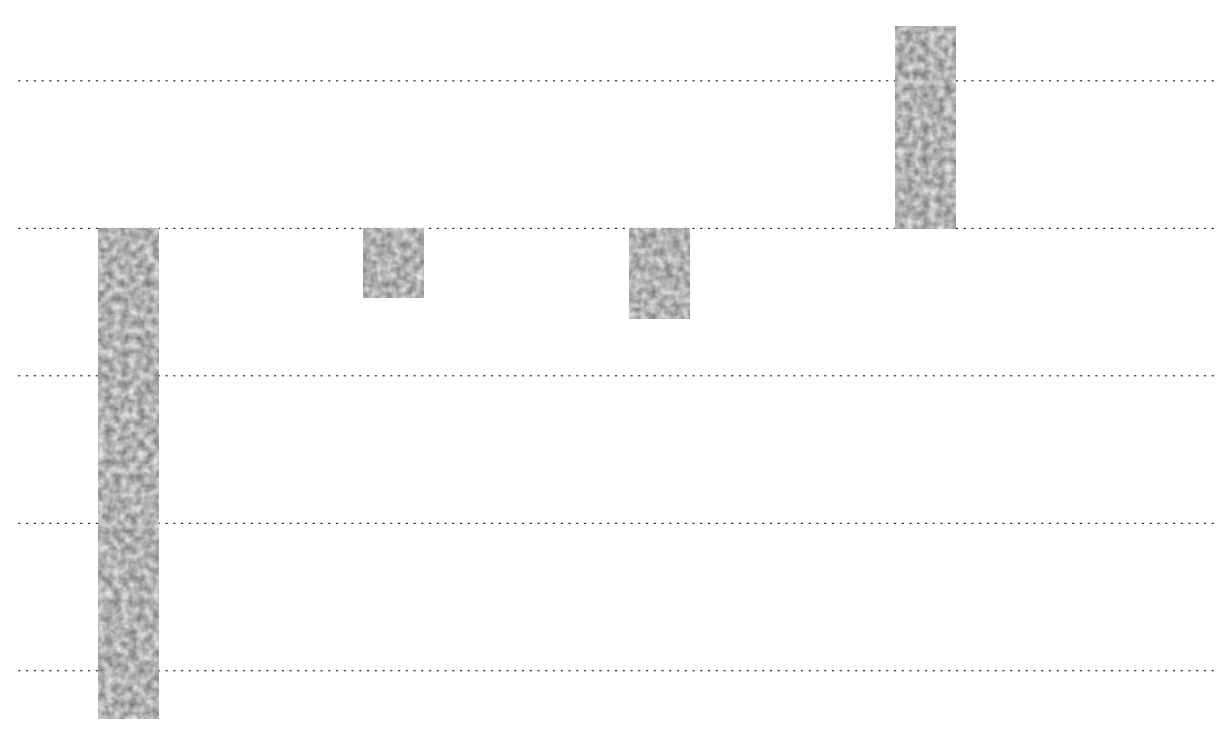

PTFE Curved Cone

Figure 2: Net Charge for PTFE actuators with pMDI formulations: HFA 134a only, HFA 134a with $1 \%$ w/w ethanol, HFA $134 \mathrm{a}$ with $15 \%$ w/w ethanol and $0.1 \%$ w/w BDP formulation containing 14.9\% w/w ethanol and 85\% w/w HFA 134a $(n=3$, $\mathrm{pC} / \mu \mathrm{g} \pm \mathrm{SD}) .(n=3, \mathrm{pC} \pm \mathrm{SD})$. 


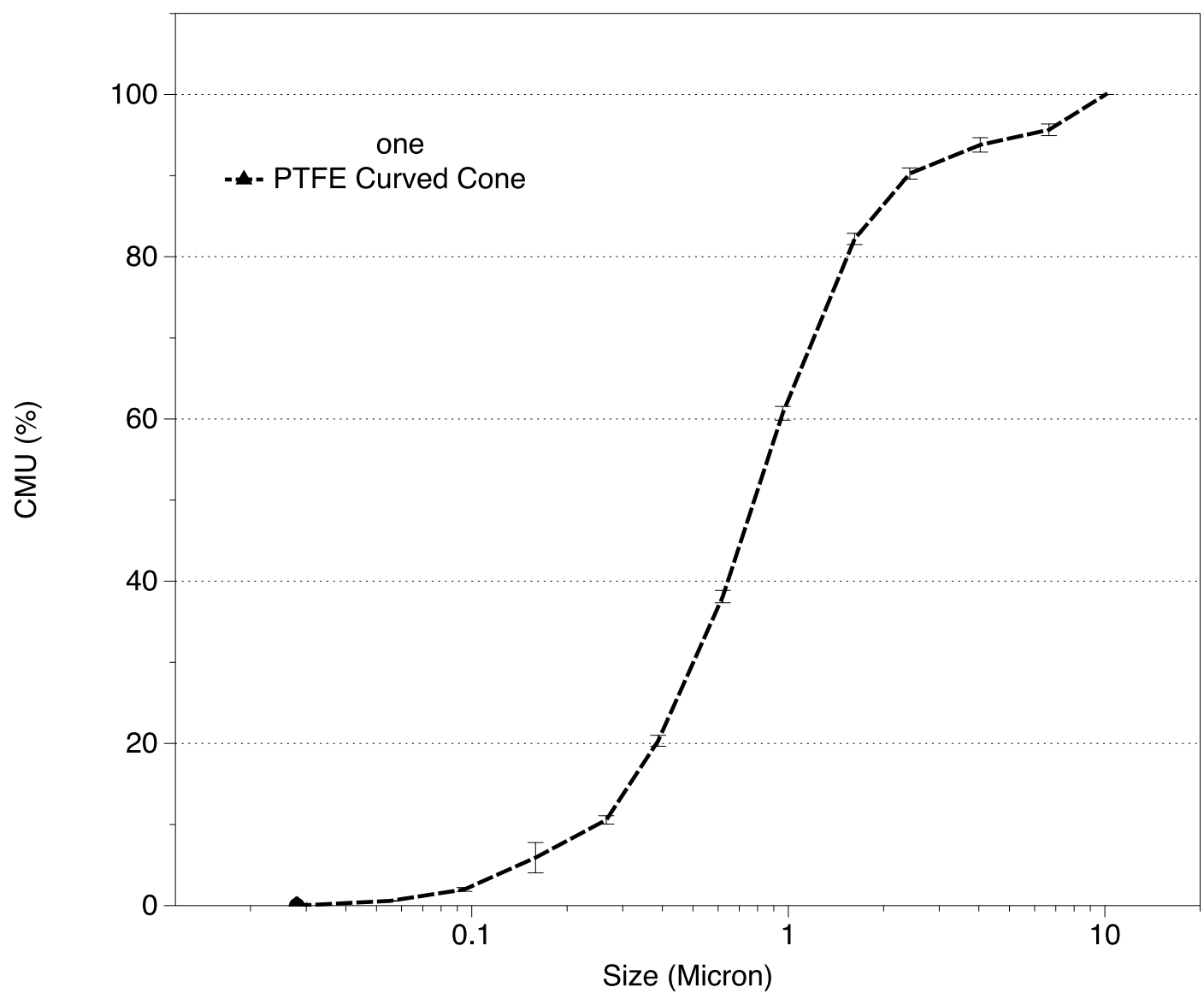

Figure 3: Cumulative mass undersize plots for PTFE actuators with 0.1\% w/w BDP formulation containing $14.9 \% \mathrm{w} / \mathrm{w}$ ethanol and $85 \% \mathrm{w} / \mathrm{w}$ HFA $134 \mathrm{a}(n=3, \% \mathrm{CMU} \pm$ SD). 


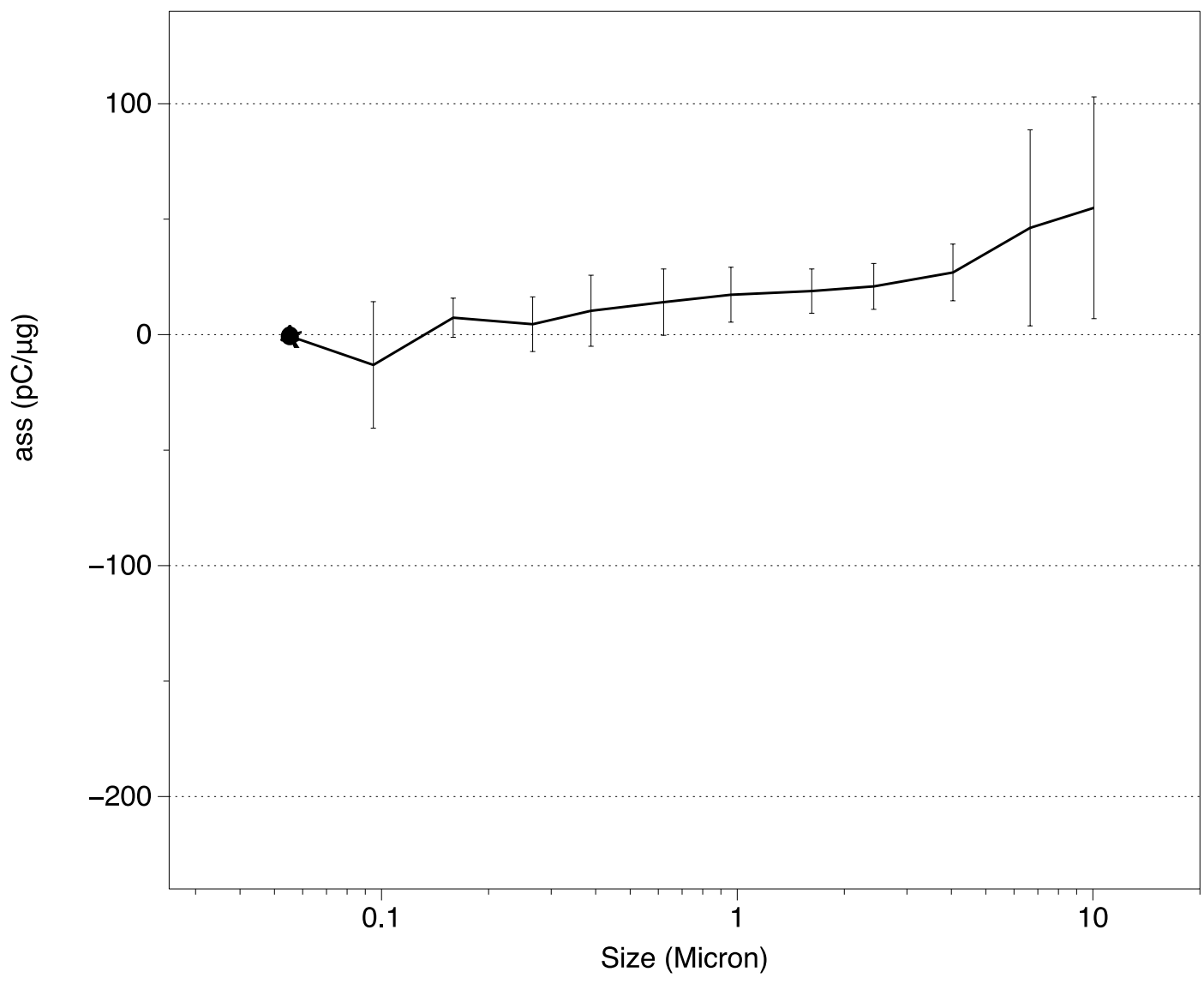

Figure 4: Charge to mass ratio for PTFE actuators with $0.1 \% \mathrm{w} / \mathrm{w}$ BDP formulation containing $14.9 \%$ w/w ethanol and $85 \%$ w/w HFA 134a $(n=3$, pC/ug \pm SD). 


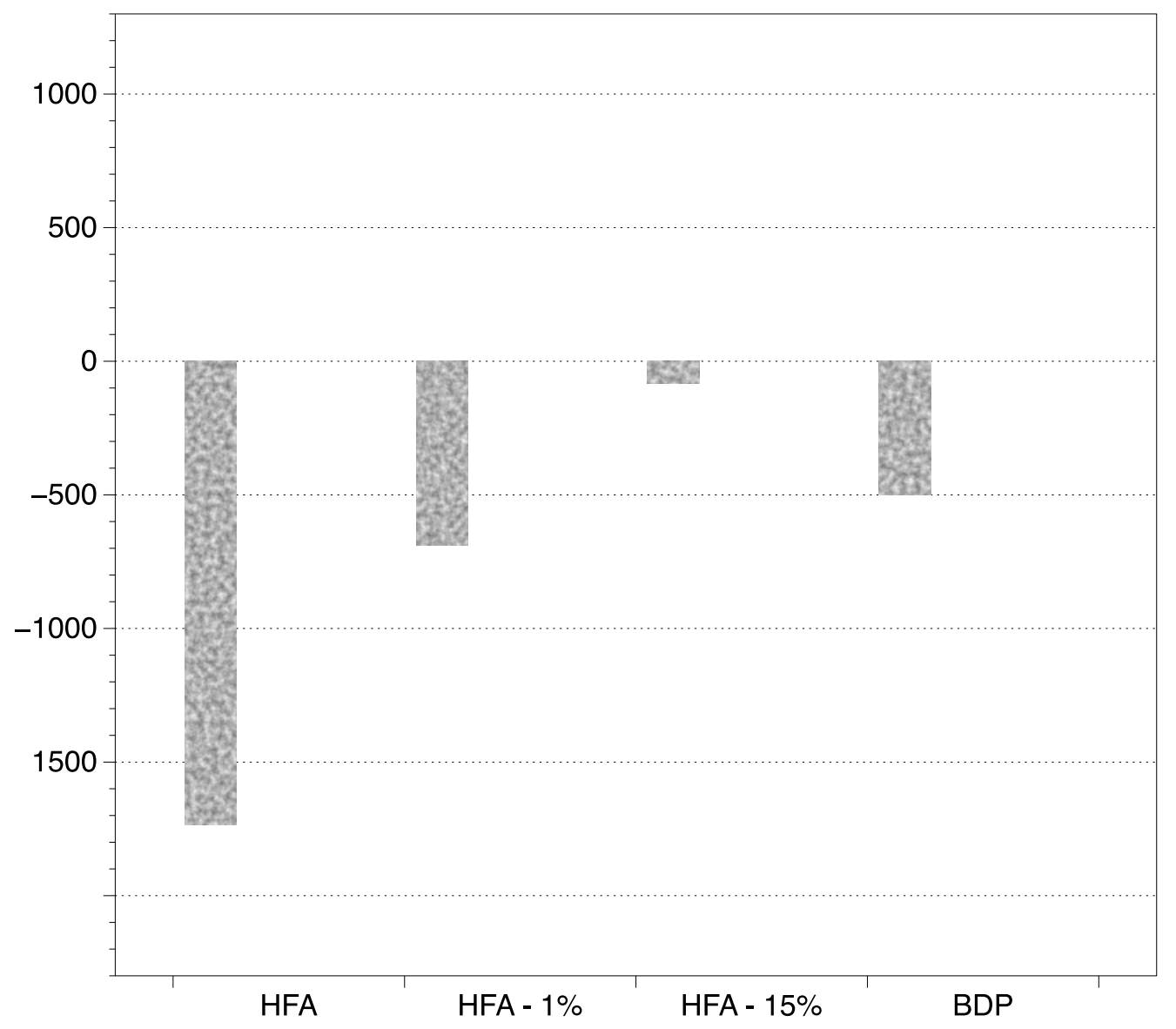

Figure 5: Net charge for PET actuators with pMDI formulations: HFA 134a only, HFA 134a with $1 \%$ w/w ethanol, HFA $134 \mathrm{a}$ with $15 \%$ w/w ethanol and $0.1 \%$ w/w BDP formulation containing 14.9\% w/w ethanol and 85\% w/w HFA 134a $(n=3$, $\mathrm{pC} / \mu \mathrm{g} \pm \mathrm{SD})$. 


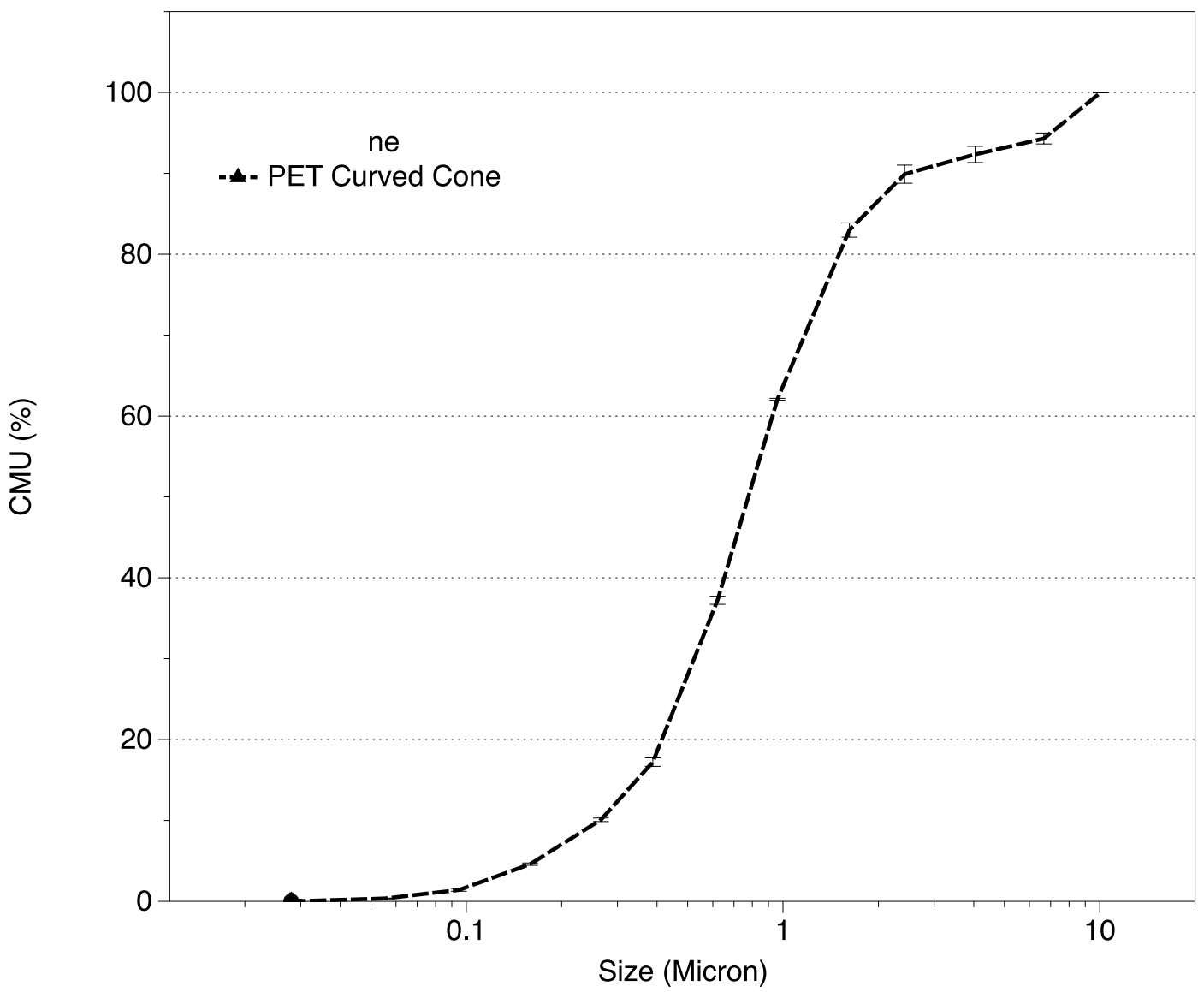

Figure 6: Cumulative mass undersize plots for PET actuators with 0.1\% w/w BDP formulation containing $14.9 \% \mathrm{w} / \mathrm{w}$ ethanol and $85 \% \mathrm{w} / \mathrm{w}$ HFA $134 \mathrm{a}(n=3, \% \mathrm{CMU} \pm$ SD). 


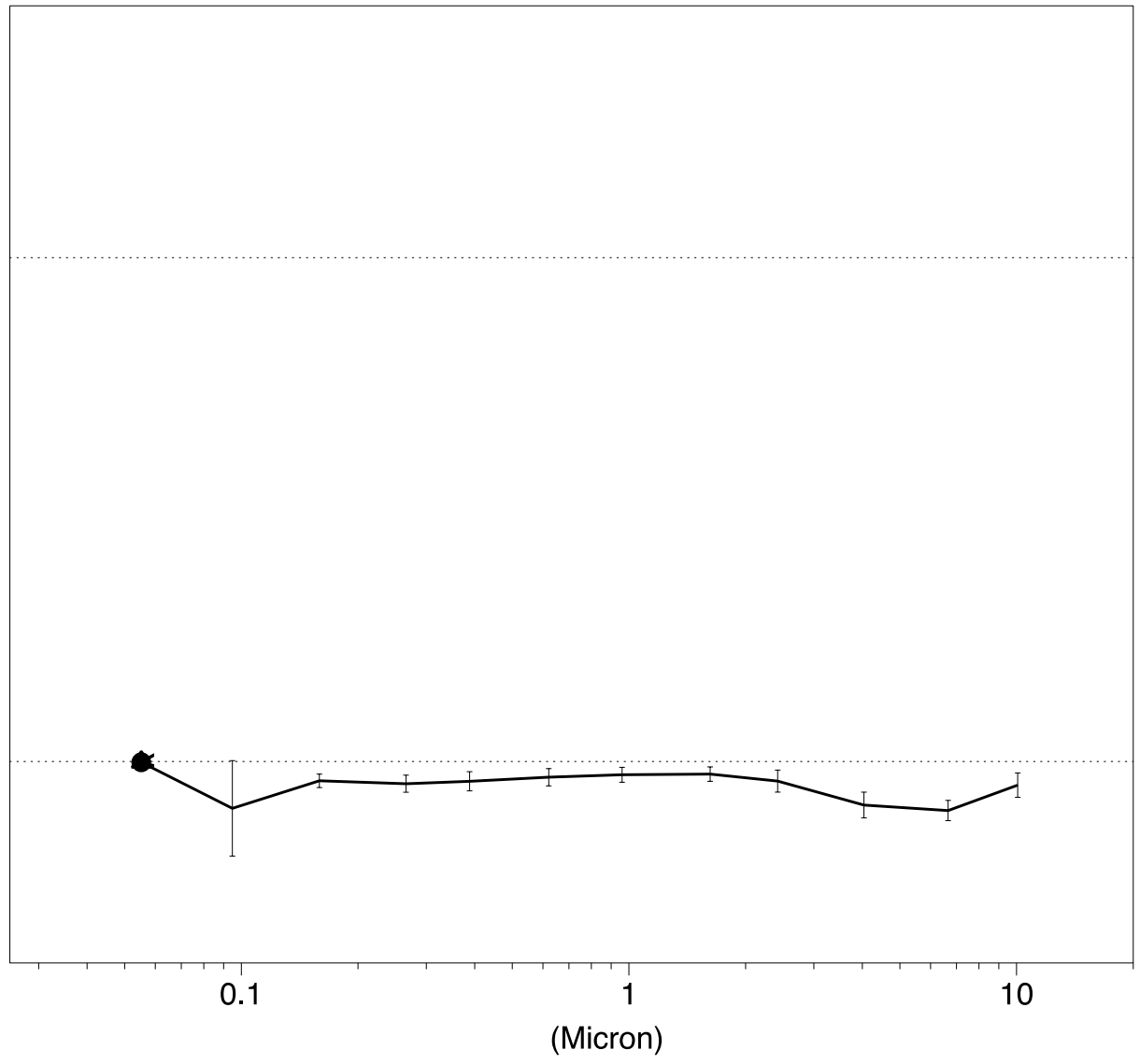

Figure 7: Charge to mass ratio for PET actuators with $0.1 \% \mathrm{w} / \mathrm{w}$ BDP formulation containing $14.9 \% \mathrm{w} / \mathrm{w}$ ethanol and $85 \% \mathrm{w} / \mathrm{w}$ HFA $134 \mathrm{a}(n=3, \mathrm{pC} / \mu \mathrm{g} \pm \mathrm{SD})$. 


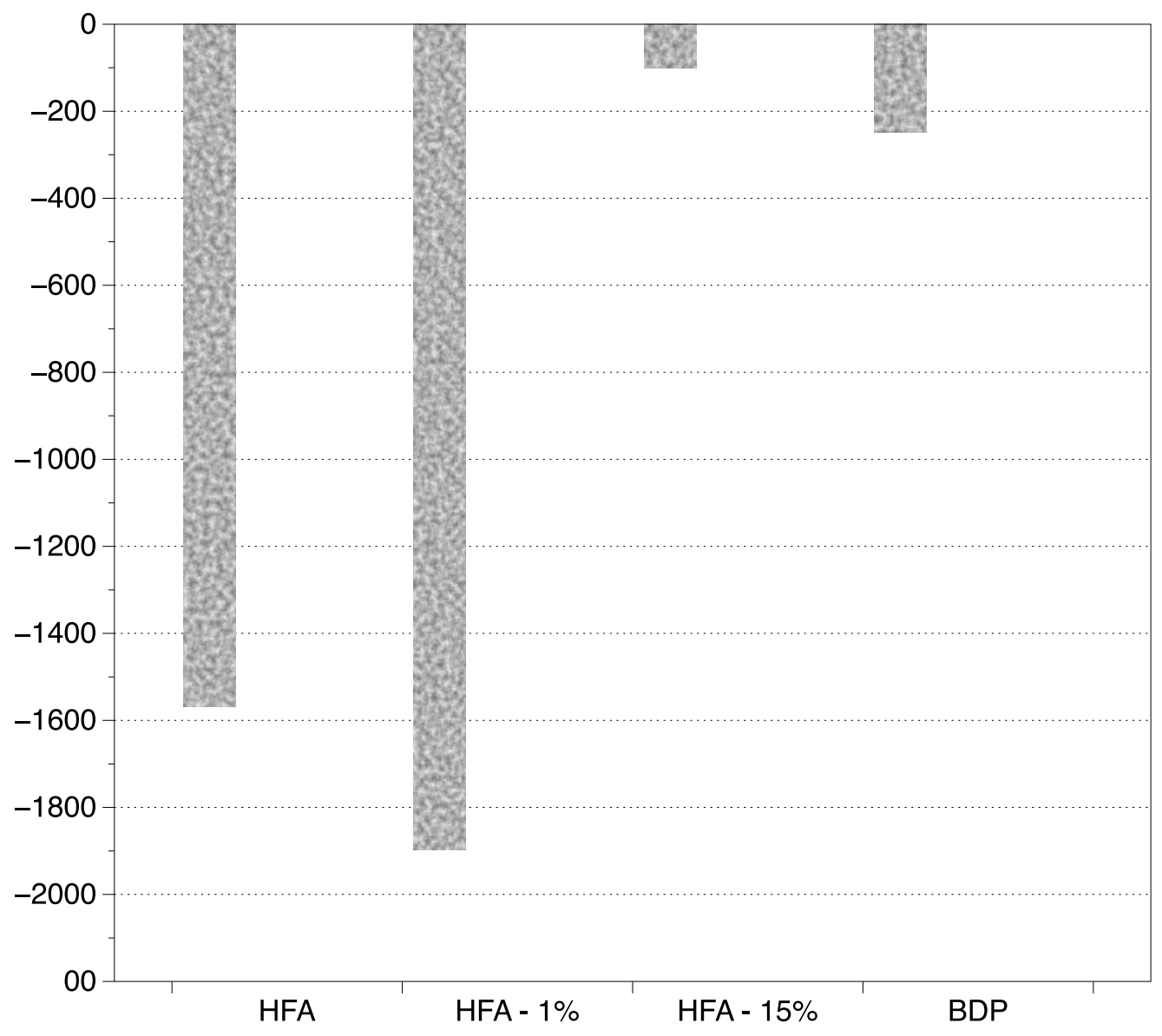

Figure 8: Net charge for aluminium actuators with pMDI formulations: HFA 134a only, HFA 134a with 1\% w/w ethanol, HFA 134a with 15\% w/w ethanol and $0.1 \%$ w/w BDP formulation containing 14.9\% w/w ethanol and 85\% w/w HFA 134a $(n=3$, $\mathrm{pC} / \mu \mathrm{g} \pm \mathrm{SD})$. 


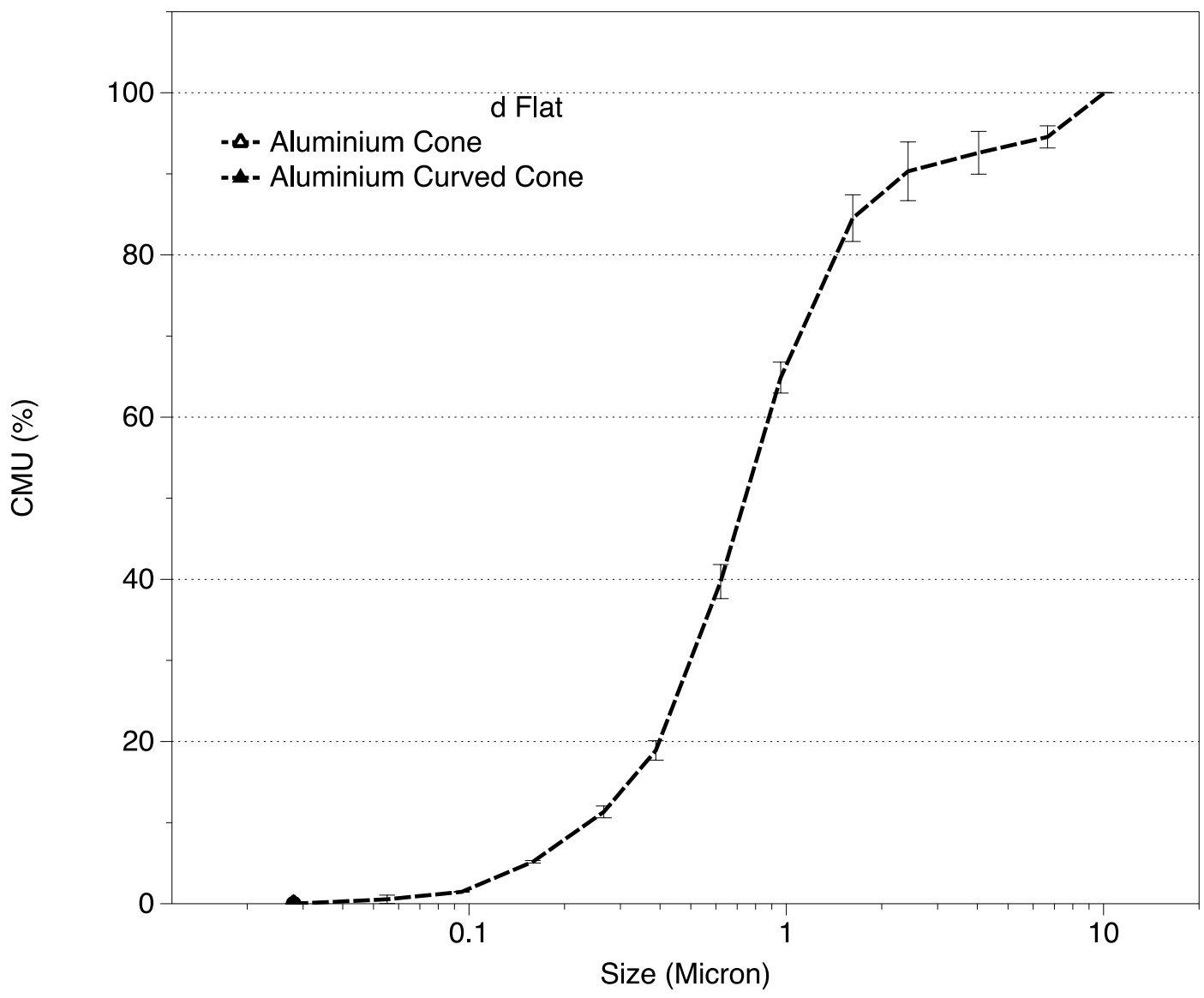

Figure 9: Cumulative mass undersize plots for aluminium actuators with $0.1 \% \mathrm{w} / \mathrm{w}$ BDP formulation containing 14.9\% w/w ethanol and 85\% w/w HFA 134a $(n=3, \%$ $\mathrm{CMU} \pm \mathrm{SD})$. 


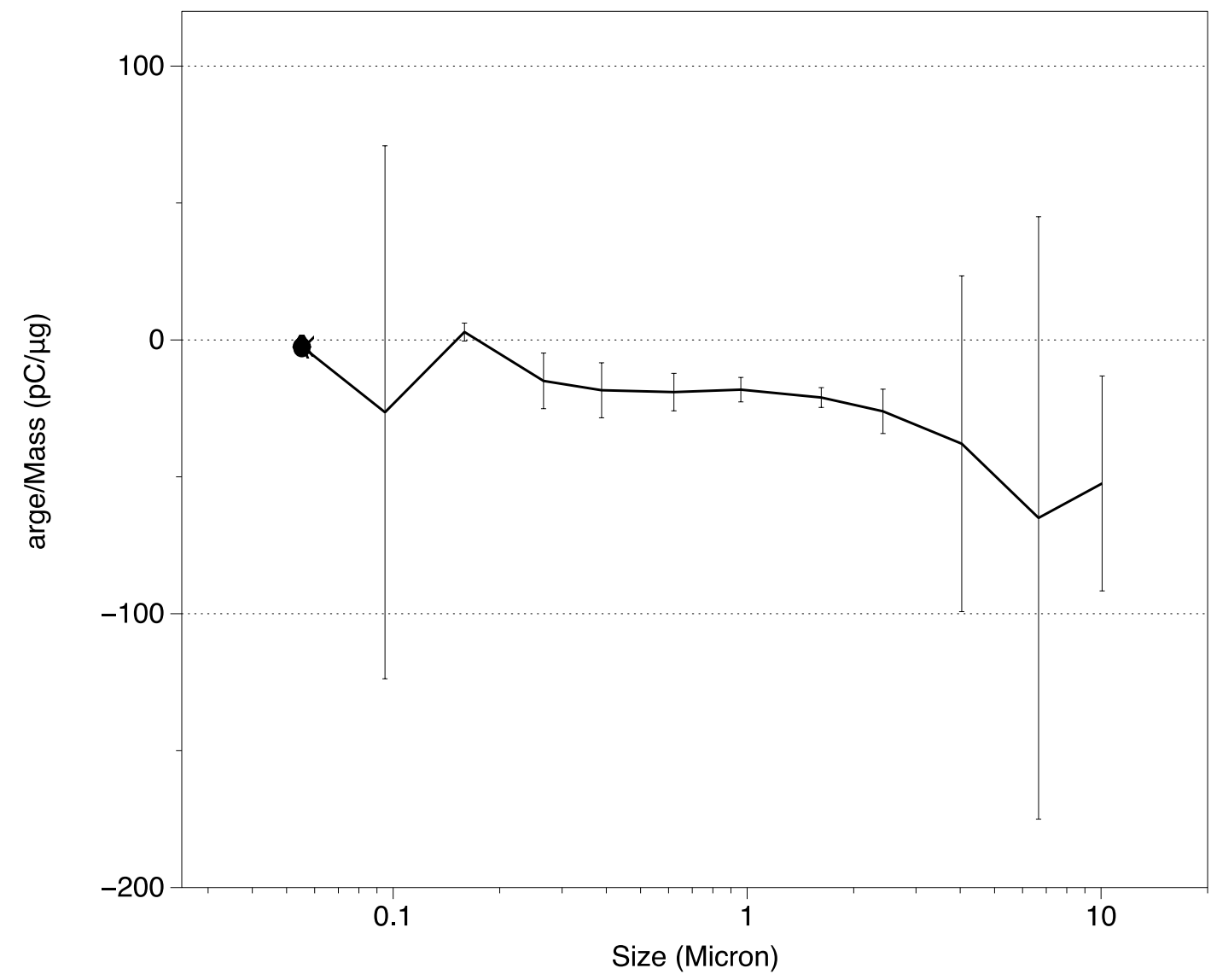

Figure 10: Charge to mass ratio for aluminium actuators with $0.1 \% \mathrm{w} / \mathrm{w}$ BDP formulation containing $14.9 \% \mathrm{w} / \mathrm{w}$ ethanol and $85 \% \mathrm{w} / \mathrm{w}$ HFA $134 \mathrm{a}(n=3, \mathrm{pC} / \mu \mathrm{g} \pm$ SD). 

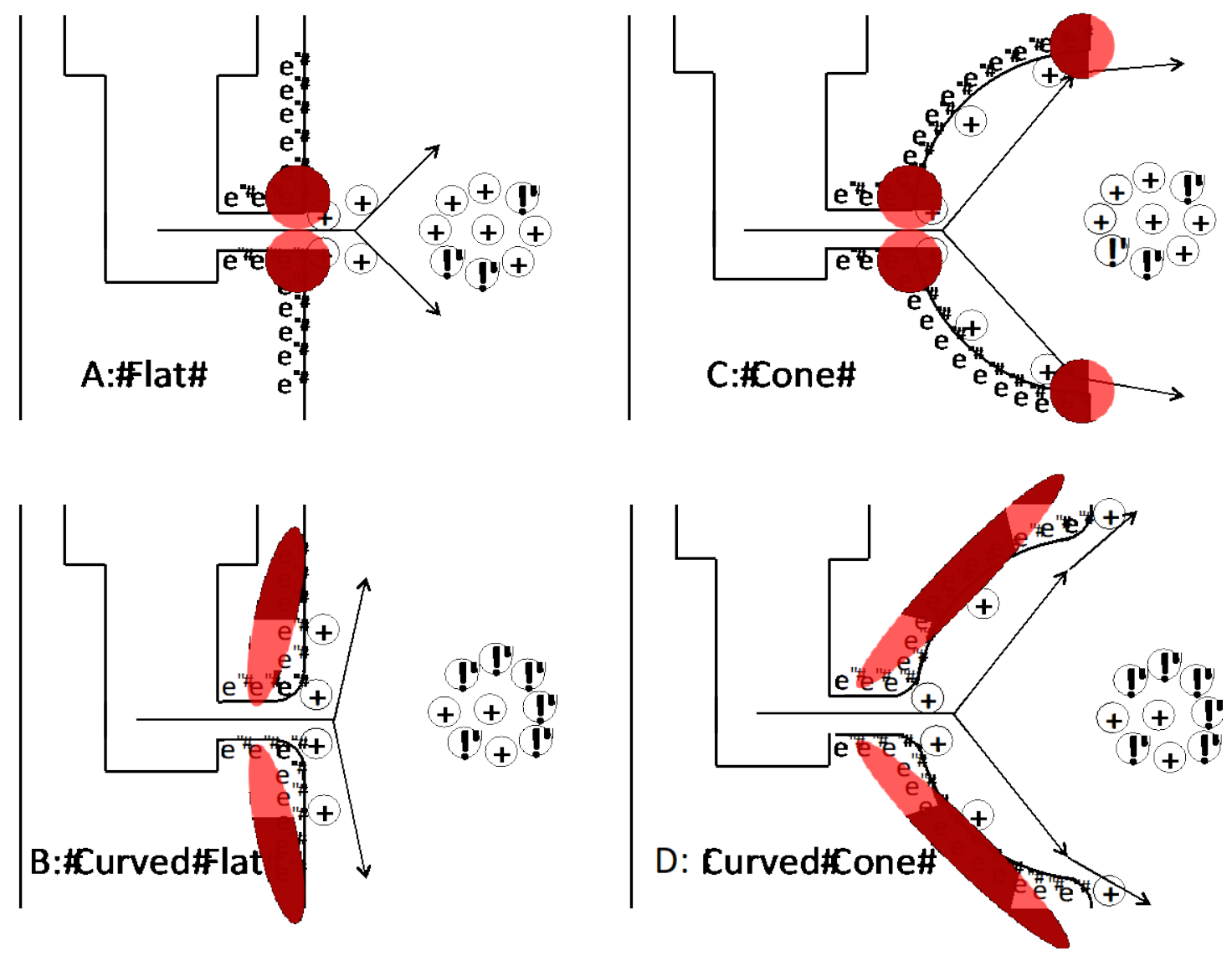

Figure 11: Hypothesis of the mechanism for electrostatic charge polarity changes between different actuator designs for material PTFE. 